\title{
Evaluation of variants in the selectin genes in age-related macular degeneration
}

\author{
Robert F Mullins ${ }^{1}$, Jessica M Skeie', James C Folk', Frances M Solivan-Timpe ${ }^{1}$, Thomas A Oetting ${ }^{1}$, Jian Huang ${ }^{2}$,
} Kai Wang ${ }^{3}$, Edwin M Stone ${ }^{1,4}$ and John H Fingert ${ }^{1 *}$

\begin{abstract}
Background: Age-related macular degeneration (AMD) is a common disease of the elderly that leads to loss of the central visual field due to atrophic or neovascular events. Evidence from human eyes and animal models suggests an important role for macrophages and endothelial cell activation in the pathogenesis of AMD. We sought to determine whether common ancestral variants in genes encoding the selectin family of proteins are associated with AMD.

Methods: Expression of E-selectin, L-selectin and P-selectin was examined in choroid and retina by quantitative PCR and immunofluorescence. Samples from patients with AMD $(n=341)$ and controls $(n=400)$ were genotyped at a total of 34 SNPs in the SELE, SELL and SELP genes. Allele and genotype frequencies at these SNPs were compared between AMD patients and controls as well as between subtypes of AMD (dry, geographic atrophy, and wet) and controls.
\end{abstract}

Results: High expression of all three selectin genes was observed in the choroid as compared to the retina. Some selectin labeling of retinal microglia, drusen cores and the choroidal vasculature was observed. In the genetic screen of AMD versus controls, no positive associations were observed for SELE or SELL. One SNP in SELP (rs3917751) produced p-values < 0.05 (uncorrected for multiple measures). In the subtype analyses, 6 SNPs (one in $S E L E$, two in SELL, and three in SELP) produced p-values $<0.05$. However, when adjusted for multiple measures with a Bonferroni correction, only one SNP in SELP (rs3917751) produced a statistically significant $p$-value ( $p=$ 0.0029).

Conclusions: This genetic screen did not detect any SNPs that were highly associated with AMD affection status overall. However, subtype analysis showed that a single SNP located within an intron of SELP (rs3917751) is statistically associated with dry AMD in our cohort. Future studies with additional cohorts and functional assays will clarify the biological significance of this discovery. Based on our findings, it is unlikely that common ancestral variants in the other selectin genes (SELE and SELL) are risk factors for AMD. Finally, it remains possible that sporadic or rare mutations in SELE, SELL, or SELP have a role in the pathogenesis of AMD.

\section{Background}

Age-related macular degeneration (AMD) is a common disease of the elderly that leads to loss of the central visual field due to atrophic or neovascular events. Prevalence rates vary between populations [1], and as many as $64 \%$ of individuals over the age of 80 may be affected to some degree [2]. Despite the common prevalence of

\footnotetext{
* Correspondence: john-fingert@uiowa.edu

'Department of Ophthalmology and Visual Sciences, The University of lowa, 200 Hawkins Drive, lowa City, IA, 52242, USA

Full list of author information is available at the end of the article
}

this disease, the molecular and cellular events that lead to AMD are not well understood.

One observation that has been made in human eyes with AMD, and in some relevant animal models, is that local inflammatory events are associated with the progression of the disease $[3,4]$. These events include elevated numbers of choroidal leukocytes and/or altered behavior of these cells in eyes with AMD [5-8]. Evidence for a potentially harmful role for monocytes and neutrophils in the etiology of choroidal neovascularization has been provided by animal models of neovascular disease, in which depletion of leukocyte populations has been
C Biomed Central 
found to ameliorate laser induced neovascularization [9-11], although the role of macrophages in mouse models of CNV may depend of the modality by which they are depleted and by the age of the mouse leukocytes used in the experiment [12,13].

The collective data indicating that the recruitment of monocytes and neutrophils into the choroid and/or retina occurs during the pathogenesis of AMD suggest that increased leukocyte trafficking occurs in AMD at the level of the choroidal microvasculature. While the process of extravasation is essential in responding to pathogens and maintaining a sterile environment, excessive inflammation can lead to tissue damage in other systems [14,15] Assuming that the mechanisms of leukocyte recruitment to the choroid are similar to those in other tissues, the principal molecules involved in this process are soluble chemokines and cell surface adhesion molecules. Among the latter are integrins, immunoglobulin superfamily members, and the selectins.

The selectins are type I transmembrane proteins characterized by an N-terminal lectin domain, an EGF like domain and a series of complement regulatory domains in the extracellular space. These proteins function in the early phases of leukocyte recruitment by promoting rolling behavior in leukocytes [16]. Similar to other endothelial cell activation molecules, expression of selectins is upregulated by a variety of insults including oxidative injury $[17,18]$ and complement attack [19]-factors widely proposed as central in the pathogenesis of AMD. Unlike other endothelial cell adhesion molecules, selectins act through protein-carbohydrate interactions, binding to carbohydrate epitopes on glycosylated target proteins [20].

In view of the role of inflammatory events and leukocyte recruitment in AMD, we hypothesized that molecules that mediate binding of leukocytes to the endothelium would be involved in the pathogenesis of AMD, and that variations in the genes that encode these adhesion molecules might be associated with the disease. To test this hypothesis, we evaluated the expression of E-selectin, L-selectin and P-selectin in the retina and choroid of aging human donor eyes. We also evaluated 34 SNPs in the SELE, SELL and SELP genes to assess whether ancestral variants in these genes contribute to the risk of AMD.

\section{Methods}

\section{Expression of selectins}

Human donor eyes were obtained from the Iowa Lions Eye Bank within 5 hours of death following informed consent of the next of kin. All experiments were performed in accordance with the tenets of the Declaration of Helsinki. Expression of selectin genes was also assessed in human retina and RPE-choroid using reverse transcriptase PCR and immunohistochemistry. Briefly, RNA was extracted from samples of normal human neural retina ( $\mathrm{n}=3$ donors) and RPE-choroid ( $\mathrm{n}=3$ donors) snap frozen with in 5 hours of death. The three donors were ages 79, 80 and 84 and had no known history of macular disease. Samples were collected immediately temporal to the macula and RNA was isolated using the RNeasy kit according to manufacturer's instructions (Qiagen, Valencia, CA). Reverse transcription was carried out using the $\mathrm{RT}^{2}$ First Strand Kit (SABiosciences, Frederick, MD) and quantitative PCR was performed using the Human Extracellular Matrix \& Adhesion Molecules Superarray (SABiosciences, Frederick, $\mathrm{MD)}$ according to the manufacturer's instructions. Values for SELE, SELL, and SELP were collected for neural retina and $\mathrm{RPE} /$ choroid and were normalized to the values for the housekeeping genes beta actin $(A C T B)$ and glyceraldehyde-3-phosphate dehydrogenase $(G A P D H)$ using the the $\Delta \Delta \mathrm{C}_{\mathrm{t}}$ method.

Immunohistochemistry was performed on human macular punches without AMD containing retina, RPE, choroid and sclera $(n>3)$. Immunohistochemistry was performed as described previously [21] using antibodies directed against P-selectin (R\&D Systems), E-selectin (Santa Cruz) and L-selectin (Santa Cruz). Antibodies were diluted $1: 50$ to $1: 200$. Primary antibodies were visualized using Alexa-488-conjugated secondary antibodies (Invitrogen; Carlsbad, CA). For P-selectin, an additional 9 eyes with early AMD, 5 eyes with end-stage wet AMD, and 9 control eyes were also evaluated with immunofluorescence. Sections were counterstained with diamidino-phenol-indole (DAPI) and for some experiments were dual-labeled with Ulex europaeus agglutinin-1 (Vector Laboratories, Burlingame, CA) which labels both normal and neovascular EC, as described previously [22].

\section{Genotyping}

The study was approved by the University of Iowa's Institutional Review board and informed consent was obtained from study participants. A cohort of 341 subjects with AMD and 400 control subjects, all from the University of Iowa Department of Ophthalmology and Visual Sciences, were enrolled using standard criteria. For the purposes of this study, AMD was defined as AREDS grade 2 or higher and patients were further categorized with either dry AMD, wet AMD, or geographic atrophy using criteria from previous studies [23]. The control subjects were judged not to have AMD after a complete eye exam. A total of 34 SNPs in the SELE, SELL, and SELP genes were selected using HAPMAP data to maximize the power to detect an association using the UCLA Association Study Design Server online software package http://design.cs.ucla.edu/. The cohorts were genotyped at 7 SNPs within the SELE gene, 11 SNPs within the SELL gene, and 16 SNPs within the SELP gene using a mass spectroscopy-based 
system (Sequenom, San Diego, CA). Genotyping was conducted using the MassArray platform and iPlex Gold reagents with the manufacturer's protocol by GeneSeek (Lincoln, NE). SNP Genotypes and allele frequencies were compared between AMD patients and controls using Chi Square analysis. For rare variants for which Chi Square test was unsuitable, we utilized the Fisher's test. The Bonferroni correction was used to adjust p-values for multiple measures using a gene-based approach to analyze 3 genes (SELP, SELL, and SELE) and 3 phenotypes (Dry AMD, GA, Wet AMD), which gave an adjusted threshold for significance of $0.05 / 9=$ 0.0056. This gene-based Bonferroni correction was validated by analyzing the contiguous genomic region spanning SELP, SELL, and SELE with the Haploview software package (data not shown). Only two strong linkage disequilibrium blocks were detected in the region (SNPs in SELL and SELE are in strong linkage disequilibrium with each other) which suggests that our correction with 3 genes may be conservative. HardyWeinberg equilibrium (HWE) was estimated by analyzing 1,000,000 simulations using the $\mathrm{R}$ statistics software package http://www.r-project.org. An arbitrary threshold for HWE was set at $p>0.001$. One SNP ( $r$ 66693963) did not meet these criteria and was removed from the analysis.

\section{Results}

\section{Expression studies}

Expression of selectin mRNAs was evaluated using a commercial quantitative PCR array. Both retina and RPE-choroid showed expression of all three selectin genes, but the normalized expression in RPE-choroid was much greater than seen in retina $(3.4 \mathrm{x}, 5.1 \mathrm{x}$, and 50.6x higher for SELL, SELE and SELP, respectively).

Selectins were localized in sections of human choroid. Overall, as assessed by immunohistochemistry, expression was similar to that seen in other vessel beds and was much weaker than generally observed in the choroid for other adhesion molecules (e.g., ICAM-1 and ICAM-2 [24]). E-selectin was observed on retinal cells we interpreted to be microglia and normal choroidal endothelial cells (Figure 1A), in addition some drusen with core domains [25] showed immunoreactivity (Figure 1C). Drusen cores were also reactive with antibodies directed against L-selectin (Figure 1D), consistent with the observation of other leukocyte antigens associated with these domains [3]. L-selectin also showed some immunoreactivity in cells we interpreted to be microglia (Figure 1B). P-selectin antibodies reacted with the choroidal endothelium of medium and large caliber vessels (Figure 2A). Reactivity was generally not observed in the microvasculature. When present, clusters of platelets were immunoreactive. We also evaluated
P-selectin labeling in a series of 18 donor eyes (9 control and 9 early AMD). Labeling intensity varied donor-todonor, without a clear relationship to disease status. Findings for P-selectin were similar to those described previously in normal and diabetic choroid [26]. Moreover, 5 eyes with neovascular AMD were also assessed with anti-P-selectin antibody. Little or no labeling was detected in the endothelial cells in the neovascular membranes (Figure 3).

\section{SNP analysis of selectin genes}

A cohort of 341 AMD patients and 400 control subjects from Iowa were genotyped at a total of 34 SNPS in the SELE, SELL, and SELP genes. Of the 341 AMD patients, 126 (37\%) had dry AMD, 41 (12\%) had geographic atrophy, and 174 (51\%) had wet AMD. High quality genotypes were obtained at $32(96 \%)$ of the 34 SNPs with an average spacing of $2.5 \mathrm{~kb}$ between each SNP and an average call rate of over 97\%. However, two SNPs in SELL were eliminated from our analysis because one was not polymorphic in our cohort (rs4987382) and the other violated HardyWeinberg equilibrium (rs6693963). The allele frequencies and genoytpe frequencies for these 30 SNPs are shown in Table 1. There was no significant difference between the AMD subjects and the control subjects when the allele frequencies and the genotype frequencies of the 15 SNPs in SELE and SELL were compared ( $\mathrm{p}>0.05$ uncorrected for multiple measures). When the allele frequencies and genotype frequencies of the 16 SNPs in SELP were compared between AMD patients and controls, one SNP (rs3917751) produced p-values $<0.05$ (uncorrected for multiple measures). However, when adjusted for multiple measures with a Bonferroni correction neither genotype nor allele $\mathrm{p}$-values are statistically significant. The other 15 SNPs in SELP produced p-values $>0.05$ (Table 1).

Patients were divided into AMD subgroups (dry AMD, wet $A M D$, and geographic atrophy and further analyzed for associations with the SNPs in SELE, SELL, and SELP (Table 2). When genotype and allele frequencies between each of these AMD subgroups and normal controls were compared, a total of six SNPs (one in SELE, two in $S E L L$, and three in $S E L P$ ) produced p-values < 0.05 . However, after multiple measures corrections, only one SNP in SELP (rs3917751) produced a statistically significant p-value of 0.0029 .

\section{Discussion}

Endothelial cell activation is a term that refers broadly to the set of responses that the endothelium undergoes to promote adhesion and extravasation of leukocytes from the lumen to the extravascular space of a tissue. Among the molecular changes that characterize endothelial cell activation is upregulation of adhesion molecules on the luminal surface of the endothelium 


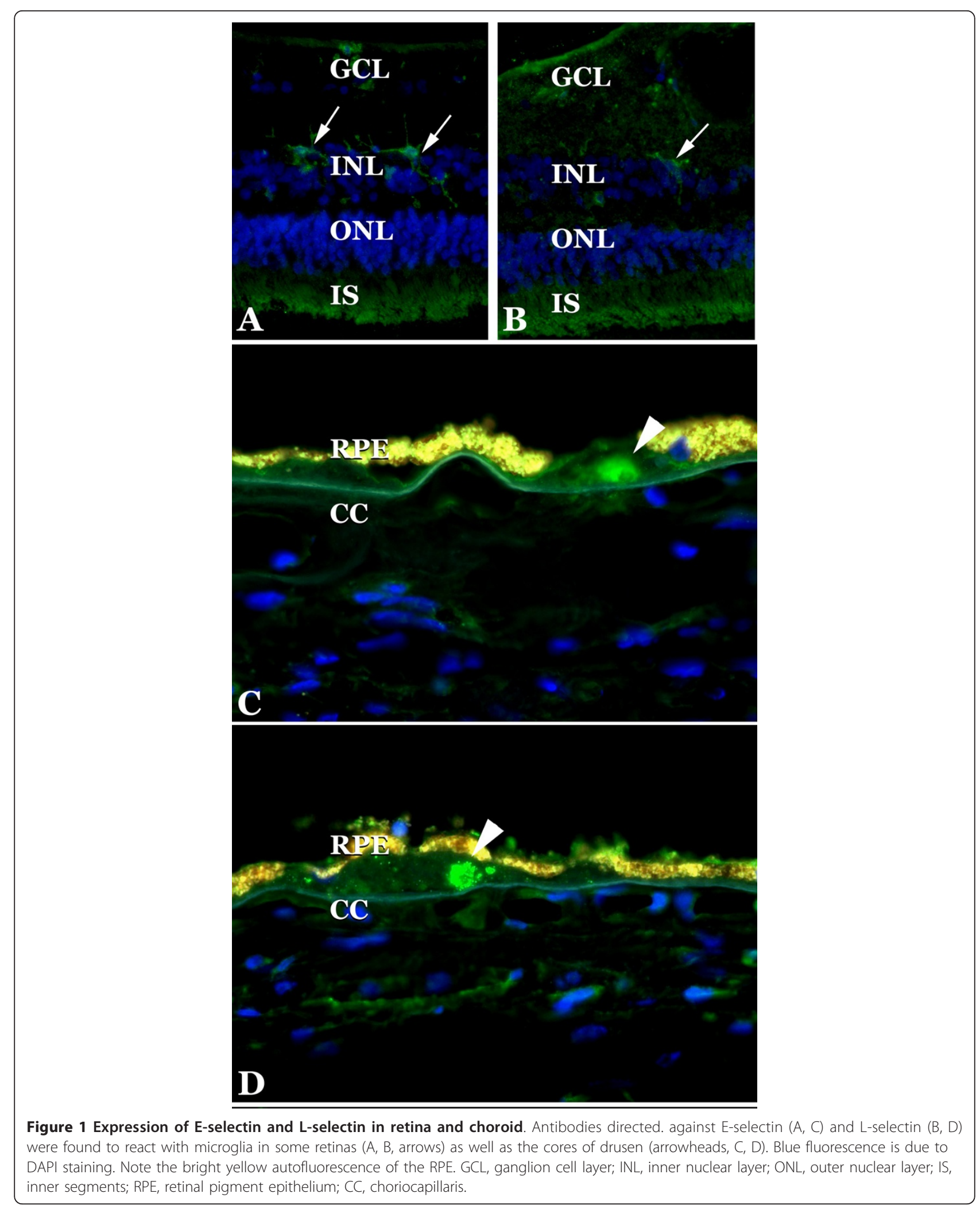



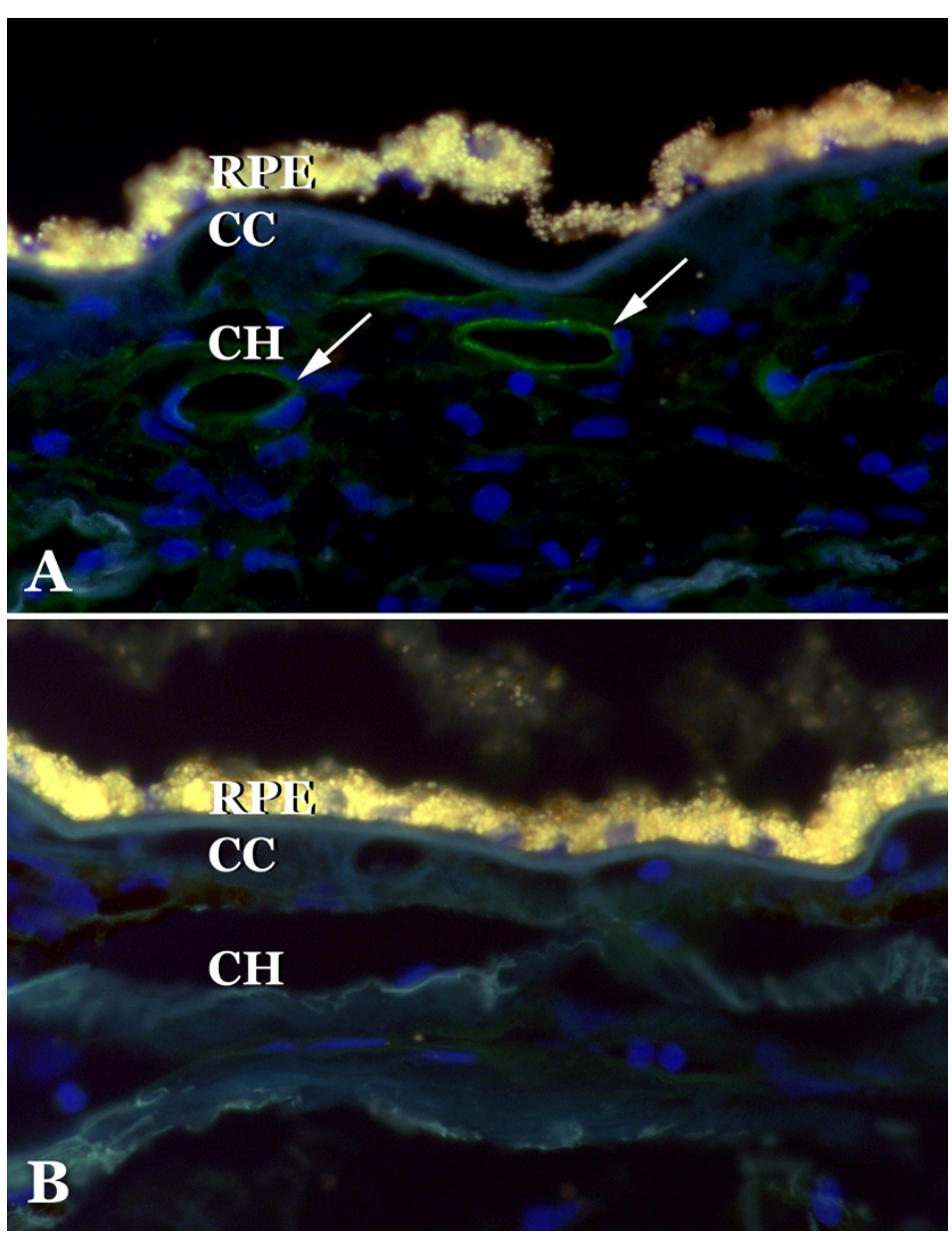

Figure 2 Localization of P-selectin to choroidal vessels. The endothelium of large choroidal vascular elements in Sattler's and Haller's layers of the choroid showed immunoreactivity with antibodies directed against P-selectin (A). Modest labeling is observed in the choriocapillaris. Labeling was not observed when the primary antibody was omitted (B). RPE, retinal pigment epithelium; CC, choriocapillaris; $\mathrm{CH}$, outer choroid.

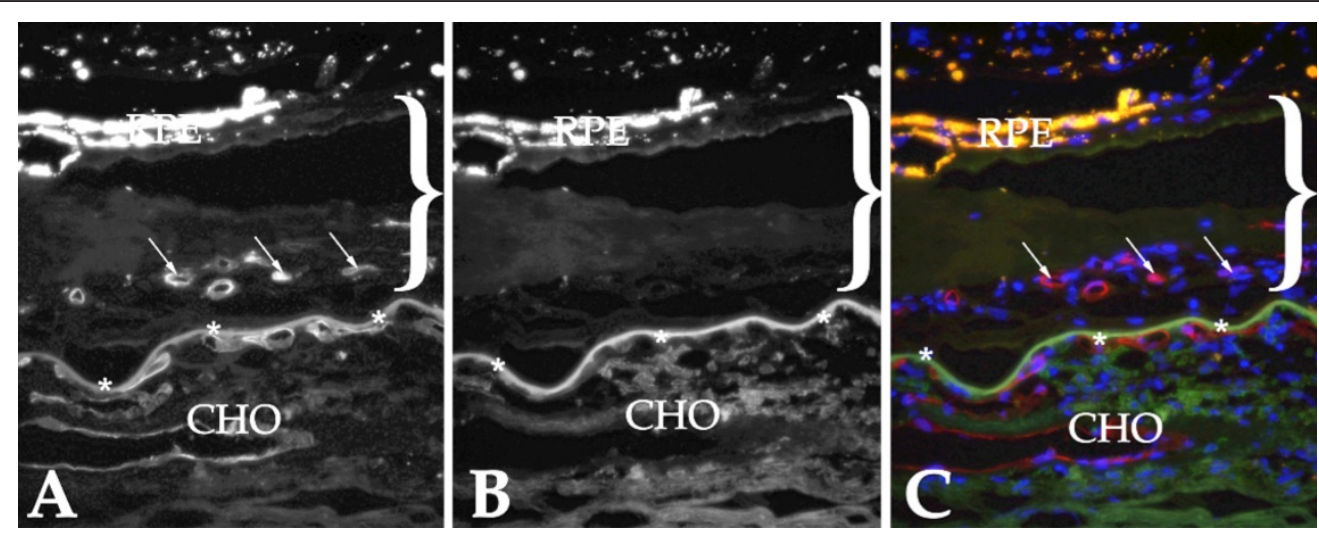

Figure 3 Evaluation of a human choroidal neovascular membrane with anti-P-selectin antibody. Sections of affected eyes were dual labeled with UEA-1 lectin, which binds both normal and neovascular endothelial cells (A), and antibodies directed against P-selectin (B). Panel C shows the merged image with DAPI (blue; UEA-I labeling appears red and anti-P-selectin labeling appears green). Labeling of the vasculature with P-selectin antibody was unremarkable. The extent of the neovascular membrane is indicated by the bracket. Arrows indicate endothelial cells within the neovascular complex and asterisks indicate points along Bruch's membrane. RPE, two layer of dystrophic RPE cells above the neovascular membrane; $\mathrm{CHO}$, choroid. 
Table 1 SNPs evaluated in SELE, SELL and SELP

\begin{tabular}{|c|c|c|c|c|c|c|c|c|c|c|}
\hline \multirow[t]{2}{*}{ Gene } & \multirow[t]{2}{*}{ rs ID } & \multirow{2}{*}{$\begin{array}{l}\text { Affect on } \\
\text { encoded } \\
\text { protein }\end{array}$} & \multirow{2}{*}{$\begin{array}{c}\text { Position on } \\
\text { chromosome } 1\end{array}$} & \multirow{2}{*}{$\begin{array}{l}\text { Spacing } \\
\text { (bp) }\end{array}$} & \multirow{2}{*}{$\begin{array}{l}\text { MAF (AMD } \\
\text { cohort) }\end{array}$} & \multirow{2}{*}{$\begin{array}{l}\text { MAF (NL } \\
\text { cohort) }\end{array}$} & \multirow{2}{*}{$\begin{array}{c}\text { MAF } \\
\text { (HapMap } \\
\text { CEU) }\end{array}$} & \multirow{2}{*}{$\begin{array}{c}\text { HWE } \\
(p- \\
\text { value })\end{array}$} & \multicolumn{2}{|c|}{ P-values } \\
\hline & & & & & & & & & $\begin{array}{c}\text { Allele } \\
\text { frequencies }\end{array}$ & $\begin{array}{c}\text { Genotype } \\
\text { frequencies }\end{array}$ \\
\hline SELE & rs4786 & - & $167,958,756$ & & 0.23 & 0.22 & 0.24 & 0.39 & 0.66 & 0.74 \\
\hline SELE & rs3917438 & - & $167,960,474$ & 1,718 & 0.068 & 0.055 & 0.05 & 0.050 & 0.33 & 0.27 \\
\hline SELE & rs5368 & His468Tyr & $167,963,570$ & 3,096 & 0.099 & 0.094 & 0.08 & 0.39 & 0.79 & 0.92 \\
\hline SELE & rs2076059 & - & $167,965,545$ & 1,975 & 0.42 & 0.42 & 0.44 & 0.019 & $>0.99$ & 0.51 \\
\hline SELE & rs3917454 & - & $167,967,477$ & 1,932 & 0.030 & 0.032 & 0.051 & 0.63 & 0.88 & 0.53 \\
\hline SELE & rs5361 & Ser149Arg & $167,967,684$ & 207 & 0.097 & 0.11 & 0.092 & 0.049 & 0.39 & 0.54 \\
\hline SELE & rs12408179 & - & $167,974,751$ & 7,067 & 0.15 & 0.17 & 0.17 & 0.24 & 0.66 & 0.46 \\
\hline SELL & rs909628 & - & $167,927,289$ & & 0.090 & 0.11 & 0.092 & $>0.99$ & 0.33 & 0.51 \\
\hline SELL & rs2298902 & - & $167,929,703$ & 2,414 & 0.11 & 0.11 & 0.12 & 0.25 & $>0.99$ & 0.85 \\
\hline SELL & rs2223286 & - & $167,932,256$ & 2,553 & 0.32 & 0.31 & 0.27 & 0.17 & 0.61 & 0.48 \\
\hline SELL & rs4987351 & - & $167,933,979$ & 1,723 & 0.48 & 0.50 & 0.45 & 0.017 & 0.49 & 0.23 \\
\hline SELL & rs2298900 & - & $167,935,644$ & 1,665 & 0.33 & 0.34 & 0.36 & 0.080 & 0.78 & 0.65 \\
\hline SELL & rs2298899 & - & $167,936,356$ & 712 & 0.093 & 0.083 & 0.075 & 0.26 & 0.52 & 0.64 \\
\hline SELL & rs4987318 & - & $167,938,102$ & 1,746 & 0.23 & 0.22 & 0.2 & 0.34 & 0.66 & 0.82 \\
\hline SELP & rs3917843 & - & $167,826,881$ & & 0.043 & 0.041 & 0.05 & $>0.99$ & 0.90 & 0.78 \\
\hline SELP & rs17522707 & - & $167,829,686$ & 2,805 & 0.097 & 0.095 & 0.058 & 0.081 & 0.85 & 0.29 \\
\hline SELP & rs6136 & Thr756Pro & $167,830,575$ & 889 & 0.10 & 0.11 & 0.092 & 0.086 & 0.55 & 0.45 \\
\hline SELP & rs1569471 & - & $167,830,754$ & 179 & 0.22 & 0.21 & 0.18 & 0.037 & 0.61 & 0.11 \\
\hline SELP & rs6133 & Val640Leu & $167,831,970$ & 1,216 & 0.12 & 0.11 & 0.12 & 0.075 & 0.75 & 0.36 \\
\hline SELP & rs6127 & Asp603Asn & $167,832,937$ & 967 & 0.49 & 0.44 & 0.48 & 0.024 & 0.11 & 0.20 \\
\hline SELP & rs3917751 & - & $167,843,192$ & 10,255 & 0.31 & 0.38 & 0.38 & 0.25 & 0.0077 & 0.018 \\
\hline SELP & rs3917740 & - & $167,845,890$ & 2,698 & 0.20 & 0.21 & 0.23 & 0.82 & 0.70 & 0.77 \\
\hline SELP & rs3917739 & - & $167,846,002$ & 112 & 0.37 & 0.37 & 0.33 & 0.18 & 0.82 & 0.72 \\
\hline SELP & rs2235304 & - & $167,846,377$ & 375 & 0.051 & 0.066 & 0.058 & 0.10 & 0.27 & 0.25 \\
\hline SELP & rs3917734 & - & $167,847,087$ & 710 & 0.30 & 0.29 & 0.32 & 0.59 & 0.73 & 0.93 \\
\hline SELP & rs6131 & Ser331Asn & $167,847,509$ & 422 & 0.16 & 0.16 & 0.22 & 0.58 & $>0.99$ & 0.62 \\
\hline SELP & rs6125 & Val209Met & $167,848,941$ & 1,432 & 0.052 & 0.050 & 0.067 & 0.25 & 0.90 & 0.90 \\
\hline SELP & rs3917686 & - & $167,857,788$ & 8,847 & 0.11 & 0.11 & 0.083 & 0.13 & 0.56 & 0.50 \\
\hline SELP & rs3917682 & - & $167,858,172$ & 384 & 0.41 & 0.40 & 0.433 & 0.066 & 0.75 & 0.41 \\
\hline SELP & rs3917681 & - & $167,858,327$ & 155 & 0.11 & 0.11 & 0.125 & 0.57 & 0.80 & 0.86 \\
\hline
\end{tabular}

MAF = Minor allele frequency. HWE = Hardy-Weinberg equilibrium. Reported p-values are uncorrected for multiple measures and those uncorrected p-values < 0.05 are shaded grey. No SNPs produced p-values below the corrected threshold for significance of 0.0042 .

(e.g., E-selectin) and/or mobilization of intracellular stores of adhesion molecules and redistribution to the cell surface (e.g., P-selectin).

We consider endothelial cell activation molecules to be attractive targets for AMD pathogenesis for the several reasons. First, leukocytes have been noted to be elevated in human eyes with AMD [5-8], as well as associated with drusen. The presence of dispersed MHC class II antigens in drusen may support a causative rather than beneficial role for choroidal leukocytes in drusen pathophysiology [3,27]. Second, depletion of monocytes $[9,10]$ and neutrophils [11] has been found to reduce the severity of neovascularization in animal models of CNV. Third, blood derived macrophages are components of neovascular membranes in human $[28,29]$ and murine [30] eyes with CNV. Moreover, targeted deletion of the Ig superfamily gene Icam 1 appears protective against experimental CNV in mouse [31], indicating a direct link between endothelial cell-leukocyte interactions and neovascularization and endothelial cell adhesion molecules, 
Table 2 Sub-group analysis of SNPs in SELE, SELL and SELP

\begin{tabular}{|c|c|c|c|c|c|c|c|c|}
\hline \multirow[t]{2}{*}{ Gene } & \multirow[t]{2}{*}{ rs ID } & \multirow{2}{*}{$\begin{array}{l}\text { Affect on } \\
\text { encoded } \\
\text { protein }\end{array}$} & \multicolumn{2}{|c|}{$\begin{array}{l}\text { Dry AMD vs. Normals Fisher's } \\
\text { extact test }\end{array}$} & \multicolumn{2}{|c|}{$\begin{array}{c}\text { GA vs. Normals Fisher's extact } \\
\text { test }\end{array}$} & \multicolumn{2}{|c|}{$\begin{array}{c}\text { Wet AMD vs. Normals Fisher's } \\
\text { extact test }\end{array}$} \\
\hline & & & $\begin{array}{c}\text { Allele } \\
\text { Frequency } \\
\text { p-value }\end{array}$ & $\begin{array}{c}\text { Genotype } \\
\text { Frequency } \\
\text { p-value }\end{array}$ & $\begin{array}{c}\text { Allele } \\
\text { Frequency } \\
\text { p-value }\end{array}$ & $\begin{array}{c}\text { Genotype } \\
\text { Frequency } \\
\text { p-value }\end{array}$ & $\begin{array}{c}\text { Allele } \\
\text { Frequency } \\
\text { p-value }\end{array}$ & $\begin{array}{c}\text { Genotype } \\
\text { Frequency } \\
\text { p-value }\end{array}$ \\
\hline SELE & rs4786 & - & 0.38 & 0.54 & 0.087 & 0.21 & 0.44 & 0.56 \\
\hline SELE & rs3917438 & - & 0.75 & 0.73 & 0.43 & 0.70 & 0.028 & 0.039 \\
\hline SELE & rs5368 & His468Tyr & 0.81 & 0.35 & 0.42 & 0.20 & 0.52 & 0.75 \\
\hline SELE & rs2076059 & - & 0.65 & 0.62 & 0.46 & 0.67 & 0.42 & 0.28 \\
\hline SELE & rs3917454 & - & $>0.99$ & $>0.99$ & 0.74 & 0.73 & $>0.99$ & 0.29 \\
\hline SELE & rs5361 & Ser149Arg & 0.91 & 0.61 & 0.35 & 0.45 & 0.47 & 0.71 \\
\hline SELE & rs12408179 & - & 0.68 & 0.92 & 0.74 & 0.71 & 0.36 & 0.13 \\
\hline SELL & rs909628 & - & $>0.99$ & 0.93 & 0.12 & 0.35 & 0.34 & 0.65 \\
\hline SELL & rs2298902 & - & 0.34 & 0.12 & 0.70 & $>0.99$ & 0.30 & 0.53 \\
\hline SELL & rs2223286 & - & 0.88 & 0.71 & 0.90 & 0.97 & 0.44 & 0.43 \\
\hline SELL & rs4987351 & - & 0.61 & 0.30 & 0.10 & 0.28 & $>0.99$ & 0.37 \\
\hline SELL & rs2298900 & - & 0.88 & 0.73 & 0.036 & 0.096 & 0.21 & 0.28 \\
\hline SELL & rs2298899 & - & 0.31 & 0.45 & 0.19 & 0.25 & 0.42 & 0.32 \\
\hline SELL & rs4987318 & - & 0.30 & 0.54 & 0.045 & 0.13 & 0.49 & 0.60 \\
\hline SELP & rs3917843 & - & 0.22 & 0.21 & 0.762 & 0.76 & 0.74 & 0.20 \\
\hline SELP & rs 17522707 & - & 0.62 & 0.72 & 0.42 & 0.92 & 0.83 & 0.26 \\
\hline SELP & rs6136 & Thr756Pro & 0.030 & 0.090 & 0.71 & 0.67 & 0.61 & 0.15 \\
\hline SELP & rs1569471 & - & 0.66 & 0.50 & 0.77 & 0.60 & 0.53 & 0.14 \\
\hline SELP & rs6133 & Val640Leu & 0.91 & 0.45 & $>0.99$ & 0.63 & 0.49 & 0.62 \\
\hline SELP & rs6127 & Asp603Asn & 0.023 & 0.041 & 0.24 & 0.50 & 0.84 & 0.94 \\
\hline SELP & rs3917751 & - & $0.0029^{*}$ & 0.0066 & 0.093 & 0.012 & 0.31 & 0.14 \\
\hline SELP & rs3917740 & - & 0.65 & 0.52 & 0.19 & 0.31 & 0.69 & 0.90 \\
\hline SELP & rs3917739 & - & 0.48 & 0.45 & 0.54 & 0.55 & 0.20 & 0.31 \\
\hline SELP & rs2235304 & - & 0.88 & 0.88 & 0.078 & 0.069 & 0.28 & 0.26 \\
\hline SELP & rs3917734 & - & 0.94 & 0.99 & 0.70 & 0.91 & 0.39 & 0.65 \\
\hline SELP & rs6131 & Ser331Asn & 0.56 & 0.35 & 0.75 & 0.54 & 0.79 & 0.94 \\
\hline SELP & rs6125 & Val209Met & $>0.99$ & $>0.99$ & 0.59 & 0.58 & 0.77 & 0.76 \\
\hline SELP & rs3917686 & - & 0.30 & 0.39 & 0.36 & 0.28 & 0.76 & 0.81 \\
\hline SELP & rs3917682 & - & 0.56 & 0.81 & 0.23 & 0.10 & 0.60 & 0.36 \\
\hline SELP & rs3917681 & - & 0.57 & 0.72 & 0.25 & 0.092 & 0.76 & 0.91 \\
\hline
\end{tabular}

Reported $p$-values are uncorrected for multiple measures and those uncorrected $p$-values $<0.05$ are indicated by bold text. One SNPs in SELP (rs3917751) that is indicated by bold text and an asterisk produced a p-value below the corrected threshold of 0.0042 .

including E-selectin, ICAM-1 and ICAM-2 have been observed in human neovascular membranes [24,32].

We evaluated expression and a number of genetic variants in the selectin genes. All three of the selectin gene products were detected at the mRNA and protein level. Both SELE and SELL were localized to cells in the inner retina with a dendritic morphology, interpreted to be retinal microglia, cells that alter their phenotype in eyes with AMD [33]. E-selectin and P-selectin were further identified on some choroidal endothelial cells, where they can bind carbohydrate epitopes on circulating leukocytes.

In light of the evidence linking endothelial cell activation molecules and AMD, we hypothesized that variants in the genes for these molecules might be skewed in AMD patients. The functional impact of variants in these genes could be difficult to predict: since the helpful or harmful roles of monocytes in AMD is somewhat 
controversial [34], it is plausible that alleles that confer either a gain or loss of function could be involved in AMD pathophysiology.

Our focused association study was designed to search for ancestral mutations in the selectin genes (SELE, $S E L L$, and $S E L P$ ) that might be common risk factors for AMD. This genetic screen did not detect any SNPs that were highly associated with AMD affection status. Our results for the SELE S149R SNP (rs5361) were similar to those of Bojanowski et al., [35] who previously genotyped this SNP in 88 AMD and 110 control samples and found no association with AMD. However, one SNP located within an intron of the P-selectin gene (rs3917751) showed a modest association with AMD overall, but given the number of SNPs and genes evaluated, this observation is not statistically significant.

When subtypes of AMD were individually analyzed, one SELP SNP (rs3917751) produced a p-value of 0.0029 that was statistically significant after correction for multiple measures. The SNP rs3917751 is located within an intron of SELP and its biological significance is unclear. Further study with additional cohorts and functional assays will likely clarify the potential role of rs3917751 and SELP in the pathogenesis of dry AMD.

Overall, the association study detected evidence of one ancestral risk allele for dry AMD in SELP (rs3917751). No associations were detected with studies of AMD overall or with wet AMD or geographic atrophy. However, as association studies are unable to identify nonancestral risk alleles, it remains possible that sporadic or rare mutations in $S E L E, S E L L$, or $S E L P$ have a role in the pathogenesis of AMD.

\section{Conclusions}

This genetic screen did not detect any SNPs that were highly associated with AMD affection status overall. However, subtype analysis showed that a single SNP located within an intron of SELP (rs3917751) is statistically associated with dry AMD in our cohort. Future studies with additional cohorts and functional assays will clarify the biological significance of this discovery. Based on our findings, it is unlikely that common ancestral variants in the other selectin genes (SELE and SELL) are risk factors for AMD. Finally, it remains possible that sporadic or rare mutations in SELE, SELL, or SELP have a role in the pathogenesis of AMD.

\section{Acknowledgements}

The authors wish to acknowledge Elizabeth A. Faidley, Jamie Tjaden and Benjamin Roos for technical support.

Supported in part by R01 EY017451 (RFM), EY016822 (EMS), EY018825 (JHF), Research to Prevent Blindness (JHF), the Macula Vision Research Foundation (RFM), and the Hansjoerg EJW Kolder MD, PhD Professorship in Best Disease Research (RFM).

\section{Author details}

${ }^{1}$ Department of Ophthalmology and Visual Sciences, The University of lowa, 200 Hawkins Drive, lowa City, IA, 52242, USA. ${ }^{2}$ Department of Statistics and Actuarial Science, The University of lowa, 241 Schaeffer Hall, lowa City, IA 52242, USA. ${ }^{3}$ Department of Biostatistics, The University of lowa, C22 General Hospital, lowa City, IA 52242, USA. ${ }^{4}$ The Howard Hughes Medical Institute, 200 Hawkins Drive, lowa City, IA, 52242, USA.

\section{Authors' contributions}

RFM contributed to the design of the study, directed and performed immunofluorescence studies, contributed to analysis of data, and participated in writing the manuscript. JMS performed immunofluorescence studies, contributed to analysis of the data, and participated in writing the manuscript. JCF examined and diagnosed patients and enrolled study subjects. FST performed immunofluorescence studies and analyzed and interpreted the genotype data. TAO examined and diagnosed patients and enrolled study subjects. JH participated in study design, directed statistical analyses, and participated in data interpretation. KW also participated in study design, directed statistical analyses, and participated in data interpretation. EMS examined and diagnosed patients and enrolled study subjects, contributed to analysis of the data, and participated in editing the manuscript. JHF participated in the study design, oversaw the genotyping studies, participated in the statistical analyses, and participated in writing the manuscript. All authors read and approved the final manuscript.

\section{Competing interests}

The authors declare that they have no competing interests.

Received: 17 September 2010 Accepted: 26 April 2011 Published: 26 April 2011

\section{References}

1. Congdon N, O'Colmain B, Klaver C, Klein R, Munoz B, Friedman D, Kempen J, Taylor H, Mitchell P: Causes and prevalence of visual impairment among adults in the United States. Arch Ophthalmol 2004, 122:477-485.

2. de Jong PT: Age-related macular degeneration. N Engl J Med 2006, 355(14):1474-1485

3. Hageman $G$, Luthert $P$, Chong $N$, Johnson L, Anderson D, Mullins R: An integrated hypothesis that considers drusen as biomarkers of immunemediated processes at the RPE-Bruch's membrane interface in aging and age-related macular degeneration. Prog Retin Eye Res 2001, 20:705-732.

4. Anderson D, Mullins R, Hageman G, Johnson L: A role for local inflammation in the formation of drusen in the aging eye. Am J Ophthalmol 2002, 134:411-431.

5. Penfold P, Killingsworth M, Sarks S: An ultrastructural study of the role of leucocytes and fibroblasts in the breakdown of Bruch's membrane. Australian Journal of Ophthalmology 1984, 12:23-31.

6. Penfold P, Killingsworth M, Sarks S: Senile macular degeneration: the involvement of immunocompetent cells. Graefe's Archives for Clinical and Experimental Ophthalmology 1985, 223:69-76.

7. Penfold P, Provis J, Billson F: Age-related macular degeneration: ultrastructural studies of the relationship of leukocytes to angiogenesis. Graefe's Arch Clin Exp Ophthalmol 1987, 225:70-76.

8. Sarks $S$, Penfold $P$, Killingsworth $M$, van Driel D: Patterns in macular degeneration. In Retinal diseases. Edited by: Ryan S, Dawson A, Little H. Orlando: Grune and Stratton; 1985:87-93.

9. Espinosa-Heidman D, Suner I, Hernandez E, Monroy D, Csaky K, Cousins S: Macrophage depletion diminishes lesion size and severity in experimental choroidal neovascularization. Investigative Ophthalmology \& Visual Science 2003, 44(8):3586-3592.

10. Sakurai E, Anand A, Ambati B, van Rooijen N, Ambati J: Macrophage depeletion inhibits experimental chorodial neovascularization. Invest Ophthalmol Vis Sci 2003, 44(8):3578-3585.

11. Zhou J, Pham L, Zhang N, He S, Gamulescu M, Spee C, Ryan S, Hinton D: Neutrophils promote experimental choroidal neovascularization. Mol Vis 2005, 11:414-424.

12. Apte RS, Richter J, Herndon J, Ferguson TA: Macrophages Inhibit Neovascularization in a Murine Model of Age-Related Macular Degeneration. PLOS Med 2006, 3(8). 
13. Kelly J, Ali Khan A, Yin J, Ferguson TA, Apte RS: Senescence regulates macrophage activation and angiogenic fate at sites of tissue injury in mice. J Clin Invest 2007, 117(11):3421-3426.

14. Donnelly S, Haslett C, Dransfield I, Robertson C, Carter D, Ross J, Grant I, Tedder T: Role of selectins in development of adult respiratory distress syndrome. Lancet 1994, 344:215-219.

15. Carden D, Xiao F, Moak C, Willis B, Robinson-Jackson S, Alexander S: Neutrophil elastase promotes lung microvascular injury and proteolysis of endothelial cadherins. Am J Physiol 1998, 275:H385-H392.

16. Ley K, Bullard D, Arbones M, Bosse R, Vestweber D, Tedder T, Beaudet A: Sequential contribution of L- and P-selectin to leukocyte rolling in vivo. Journal of Experimental Medicine 1995, 181:669-675.

17. Rahman A, Kefer J, Bando M, Niles WD, Malik AB: E-selectin expression in human endothelial cells by TNF-alpha-induced oxidant generation and NF-kappaB activation. Am J Physiol 1998, 275(3 Pt 1):L533-544.

18. Patel KD, Zimmerman GA, Prescott SM, McEver RP, McIntyre TM: Oxygen radicals induce human endothelial cells to express GMP-140 and bind neutrophils. J Cell Biol 1991, 112(4):749-759.

19. Bless NM, Tojo SJ, Kawarai H, Natsume $Y$, Lentsch AB, Padgaonkar VA, Czermak BJ, Schmal H, Friedl HP, Ward PA: Differing patterns of P-selectin expression in lung injury. Am J Pathol 1998, 153(4):1113-1122.

20. Sperandio M, Gleissner CA, Ley K: Glycosylation in immune cell trafficking. Immunol Rev 2009, 230(1):97-113.

21. Mullins R, Kuehn M, Faidley E, Syed N, Stone E: Differential macular and peripheral expression of bestrophin in human eyes and its implication for Best disease. Invest Ophthalmol Vis Sci 2007, 48:3372-3380.

22. Mullins R, Grassi M, Skeie J: Glycoconjugates of choroidal neovascular membranes in age-related macular degeneration. Mol Vis 2005, 11:509-517.

23. A randomized, placebo-controlled, clinical trial of high-dose supplementation with vitamins $C$ and $E$, beta carotene, and zinc for age-related macular degeneration and vision loss. Arch Ophthalmol 2001, 119:1417-1436.

24. Mullins R, Skeie J, Malone E, Kuehn M: Macular and peripheral distribution of ICAM-1 in the human choriocapillaris and retina. Mol Vis 2006, 12:224-235.

25. Mullins R, Hageman G: Human ocular drusen possess novel core domains with a distinct carbohydrate composition. Journal of Histochemistry and Cytochemistry 1999, 47:1533-1539

26. McLeod D, Lefer D, Merges C, Lutty G: Enhanced expression of intracellular adhesion molecule-1 and P-selectin in the diabetic human retina and choroid. American Journal of Pathology 1995, 147(3):642-653.

27. Mullins R, Anderson D, Russell S, Hageman G: Ocular drusen contain proteins common to extracellular deposits associated with atherosclerosis, elastosis, amyloidosis, and dense deposit disease. FASEB Journal 2000, 14:835-846.

28. Grossniklaus HE, Ling JX, Wallace TM, Dithmar S, Lawson DH, Cohen C, Elner VM, Elner SG, Sternberg P Jr: Macrophage and retinal pigment epithelium expression of angiogenic cytokines in choroidal neovascularization. Mol Vis 2002, 8:119-126.

29. Grossniklaus H, Cingle K, Yoon Y, Ketkar N, L'Hernault N, Brown S: Correlation of histologic 2-dimensional reconstruction and confocal scanning laser microscopic imaging of choroidal neovascularization in eyes with age-related maculopathy. Arch Ophthalmol 2000, 118:625-629.

30. Csaky K, Baffi J, Byrnes G, Wolfe J, Hilmer S, Flippin J, Cousins S: Recruitment of marrow-derived endothelial cells to experimental choroidal neovascularization by local expression of vascular endothelial growth facto. Exp Eye Res 2004, 78:1107-1116.

31. Sakurai E, Taguchi H, Anand A, Ambati B, Gragoudas E, Miller J, Adamis A, Ambati J: Targeted disruption of the CD18 or ICAM-1 gene inhibits choroidal neovascularization. Invest Ophthalmol Vis Sci 2003, 44:2743-2749.

32. Yeh D, Bula D, Miller J, Gragoudas E, Arroyo J: Expression of leukocyte adhesion molecules in human subfoveal choroidal neovascular membranes treated with and without photodynamic therapy. Invest Ophthalmol Vis Sci 2004, 45:2368-2373.

33. Penfold PL, Liew SC, Madigan MC, Provis JM: Modulation of major histocompatibility complex class II expression in retinas with age-related macular degeneration. Investigative Ophthalmology \& Visual Science 1997, 38(10):2125-2133.

34. Skeie J, Mullins R: Macrophages in neovascular age-related macular degeneration: friends or foes? Eye 2008.
35. Bojanowski CM, Tuo J, Chew EY, Csaky KG, Chan CC: Analysis of Hemicentin-1, hOgg1, and E-selectin single nucleotide polymorphisms in age-related macular degeneration. Trans Am Ophthalmol Soc 2005, 103:37-44, discussion 44-35.

\section{Pre-publication history}

The pre-publication history for this paper can be accessed here: http://www.biomedcentral.com/1471-2350/12/58/prepub

doi:10.1186/1471-2350-12-58

Cite this article as: Mullins et al:: Evaluation of variants in the selectin genes in age-related macular degeneration. BMC Medical Genetics 2011 12:58.

\section{Submit your next manuscript to BioMed Central and take full advantage of:}

- Convenient online submission

- Thorough peer review

- No space constraints or color figure charges

- Immediate publication on acceptance

- Inclusion in PubMed, CAS, Scopus and Google Scholar

- Research which is freely available for redistribution

Submit your manuscript at www.biomedcentral.com/submit
C) Biomed Central 